\title{
ANATOMIA DEL ERROR EN RADIOLOGIA
}

\section{Dr. César García M.}

Servicio de Radiología. Clínica Alemana de Santiago.

\begin{abstract}
Medical activity is practised in uncertainty. This implies a high-risk environment. It is necessary to adopt measures and make interventions designed to contain medical risks and errors, improving healthcare safety. A profound knowledge is required to deal with mechanisms of error in our speciality and introduce the necessary actions to prevent and correct errors, acting over people, work systems and institutions.
\end{abstract}

Key words: Departmental management, Radiology and radiologists, Socio-economic issues.

Resumen: La actividad médica, por su naturaleza, se desarrolla en un ambiente de incertidumbre, ya que sus resultados no son constantes en respuesta a actos médicos iguales, y por ello es una función de alto riesgo, siendo necesarias medidas y acciones para disminuirlo y aumentar la seguridad de la atención médica. Esto implica un conocimiento adecuado del error en el área médica en que nos desempeñamos, una cuantificación lo más ajustada posible de éste y la adopción de medidas preventivas $y$ correctivas sobre personas, sistemas en los que estas trabajan e instituciones.

Palabras claves: Manejo departamental, Radiología y radiólogos.

\section{Introducción}

El error en medicina ha existido siempre ya que es una actividad humana ligada a la incertidumbre y al riesgo. Por este motivo, la pregunta que debemos formularnos como radiólogos es ¿Cuánto error es aceptable en Radiología? y después de contestarla basados en estudios prospectivos 0 retrospectivos, plantearnos la segunda interrogante "¿Qué podemos hacer para prevenir, disminuir o impedir que siga aumentando?"(1)

García C. Anatomía del error en radiología. Rev Chil Radiol 2003; 9: 144-150.

Correspondencia: Dr. César García M.

Servicio de Radiología. Clínica Alemana de Santiago. cgarcia@alemana.cl
Basados en las comunicaciones publicadas en la literatura a nuestro alcance, podemos conocer el nivel de error en aquellos sitios que se preocupan del problema y emprender la importante tarea de tratar de cuantificar el mismo en nuestras instituciones 0 sitios de trabajo, a través de los reclamos del público, demandas o estudios diseñados para el efecto(2).

Para poder lidiar con el error debemos hacernos una serie de preguntas: ¿Qué es el error?, ¿Cómo podemos cuantificarlo?, ¿En que consiste el error en radiología?, ¿Cómo podemos controlarlo?, ¿Qué hacemos si se escapa de nuestro control? $?^{(3,4)}$

\section{I. ¿Qué es el error?}

Hay muchos tratados que cruzan transversalmente varias disciplinas tratando de dar una definición. Es una labor difícil. Coloquialmente, podríamos deducir que quién se equivoca (quienquiera que sea) podría haberlo hecho mejor. Sin embargo, esto explica solo parte de los hechos, dado que siempre hay algún grado de discrepancia con el resultado final. Visto de este modo, deberíamos darnos cuenta que al hablar de error, éste es solo una medida de la varianza del resultado perfecto. Dicho sea de paso, no hay ningún test $\sin$ falsos positivos o negativos ${ }^{(5)}$.

De acuerdo a esto, al hablar de un rango amplio de errores, deberíamos preocuparnos, al menos al comienzo, de aquellas discrepancias que conducen a un "error grave" o «evento adverso importante» que resulta en un cambio desfavorable en el resultado final de un paciente.

No obstante, no debemos dejar pasar desapercibidos los "errores menores", dado que estudios provenientes del ámbito de la prevención de riesgo en la aviación demuestran que aquellas tripulaciones que tienden a cometer más "errores menores" (mishaps) tienen más probabilidades de tener uno con consecuencias graves ${ }^{(6)}$.

\section{II. ¿Cómo cuantificar el error?}

Tenemos dos grandes métodos para obtener información y tratar de cuantificar en la forma más 
ajustada posible la magnitud del error. Por un lado, están las revisiones o investigaciones prospectivas 0 retrospectivas del error, principalmente en pacientes hospitalizados en grandes instituciones. Esto se ha hecho en países anglosajones con resultados controvertidos. Uno de estos estudios, el informe Corrigan, dado a conocer en 1999, comunica una tasa de error bastante alta en la práctica médica en EEUU: 44.000-98.000 muertes anuales atribuibles a error; 7.000 muertes al año ligadas a errores de "medicación" la mayor parte evitables( ${ }^{(7)}$.

No tenemos conocimiento de algún estudio de similares características en nuestro país.

El segundo método para recopilar información es casi cualitativo y sólo nos da una idea aproximada del problema y consiste en examinar los reclamos y las demandas judiciales de los pacientes insatisfechos, lo que nos pude indicar una tendencia y nos permite analizar y corregir las posibles fallas en las personas y los sistemas. En Chile, es el método que podemos aplicar más fácilmente en nuestras instituciones, departamentos de imágenes o servicios de radiología.

\section{III. ¿En que consiste el error en radiología? ¿Cómo podemos controlarlo?}

En general, el error en la práctica médica puede ser reducido de manera significativa, pero nunca erradicado. Se suele dividir en tres grupos principales $^{(8)}$.

a) "No fault errors": Son cometidos cuando la enfermedad es de presentación tórpida, atípica o simula otra de ocurrencia más frecuente. Tienden a reducirse con el adelanto de las ciencias médicas, la identificación de nuevos síndromes, con lo que las enfermedades se pueden diagnosticar con mayor precisión y de manera más precoz. Nunca podrán ser eliminados, porque aparecen nuevas enfermedades, ningún test diagnóstico es perfecto, a veces los pacientes son poco "quejumbrosos" y, en ocasiones, los médicos elegirán inevitablemente el diagnóstico más frecuente en lugar del correcto, ilustrando de este modo el concepto de la necesaria falibilidad y la naturaleza probabilística de escoger un diagnóstico. b) Errores de los sistemas: tienen su rol cuando el diagnóstico se retrasa o se deja de hacer debido a imperfecciones latentes en los sistemas de atención sanitaria. Se pueden reducir con mejoras en los sistemas, pero no eliminar por completo debido a que las mejorías quedan atrás y se degradan con el paso del tiempo; además, cada nueva norma implementada es una oportunidad para nuevos errores. c) Errores cognoscitivos: Son diagnósticos erróneos debidos a fallas en la recolección de datos o en su interpretación, razonamiento imperfecto 0 conocimientos insuficientes. Las limitaciones de los procesos humanos y los sesgos inherentes a la heurística (dícese de lo que ayuda al descubrimiento o interpretación de hechos o verdades) garantizan la persistencia de estos errores. Tenemos sin embargo la oportunidad de mejorar el aspecto cognoscitivo del diagnóstico mediante la adopción de cambios en los distintos niveles de los sistemas diagnósticos ya sea con segundas opiniones, sistemas de apoyo a las decisiones o mejoras en el acceso a los especialistas y diseñando programas para mejorar conocimientos, destrezas o habilidades.

En la práctica de la radiología podemos identificar estos tres tipos de error diagnóstico, pero debido a la manera particular de trabajar en la especialidad, debemos adoptar otro enfoque, más práctico. Así, los dividiremos en:

1. Errores de logística o fallas del proceso radiológico no relacionados directamente con el acto diagnóstico del médico. Asociados con trascripción, marcación de exámenes, indicaciones pre o post exámenes, pérdidas de éstos, errores en la entrega, confusión de exámenes o informes y otros.

Los errores de logística, parecieran ser menos importantes; sin embargo, no es así, dado la forma como los radiólogos ejercen la especialidad, en la que el contacto directo con los pacientes es poco frecuente, salvo excepciones como el ultrasonido o la radiología intervencional. Para muchos pacientes, el radiólogo, el cual ellos no eligen, no es su médico y es percibido como un nombre sin rostro, y la opinión que ellos se forman de él va a estar fuertemente influenciada por el trato y la atención brindada por el personal del Servicio. Esto es importante, dado que un evento adverso por sí solo es un determinante menor en la decisión de demandar o no, siendo más importantes las consideraciones de humanitarismo y calidez de la atención recibida, en cuyo caso el error es percibido como un evento esperable en el curso de la evolución.

De ahí la necesidad de desarrollar técnicas de manejo de riesgo para cargos o empleados específicos (recepcionistas, telefonistas, transcriptoras, auxiliares de sala, tecnólogos médicos, y personal de turnos nocturnos y fines de semana), con medidas destinadas a actuar sobre las personas

i. Evento adverso: Daño causado por acción médica más que por las condiciones inherentes del paciente que puede o no ser atribuido a error. 
(entrenamiento, capacitación, estímulos) y sobre los sistemas (normas de atención telefónica, de presentación ante el paciente, de atención profesional cálida y cortés, etc.), con evaluaciones periódicas e implementación de medidas correctivas si es necesario( ${ }^{(9)}$.

2. Errores en el proceso diagnóstico, relacionados directamente con la interpretación que el radiólogo hace de un examen o los resultados de un procedimiento diagnóstico o terapéutico.

En otras palabras, podemos decir que aquí el radiólogo no ve, no informa, no consulta o confunde la interpretación de los signos radiológicos. Se han clasificado en errores de percepción, aliterativos, asociados a falta de conocimientos o especialización y a no revisar las imágenes con el clínico.

2 a. Error de percepción, es el más importante de éstos y bordea entre un $60 \%$ a un $80 \%$ del total de los errores. De las publicaciones sobre error en radiología inferimos que es de difícil disminución, solo podemos hacer esfuerzos para que no aumente, e idealmente disminuirlo. ¿En que consisten? Kopans lo describe como "caprichos de percepción, interrupción perceptual ajena a negligencia que correspondería más bien a un fenómeno «psicovisual inmutable". Aún no sabemos por que omitimos, no vemos o no informamos hallazgos radiográficos que en retrospectiva son obvios ${ }^{(10-12)}$.

Asociados a los errores de percepción, existen varios factores que podemos denominar los inductores del error, elementos facilitadores para que el radiólogo no vea, no informe, o confunda la interpretación de los signos radiológicos: entre ellos destacan técnica radiológica deficiente o protocolos de exámenes inadecuados, interpretaciones muy lentas o muy rápidas, informar solo un hallazgo y no todos, omitir el signo radiológico sin darle la importancia que tiene, no disponer de los antecedentes clínicos, efectuar informes no comparativos, carecer de conocimientos actualizados $^{(13-16)}$

El control del error de percepción es nuestro principal objetivo ya que es el más frecuente. Una buena manera de abordarlo es gestionar el riesgo asociado con lo que definimos como los inductores del error de percepción.

Técnica radiológica deficiente o protocolos de exámenes inadecuados: el control de los factores técnicos de nuestras modalidades diagnósticas o terapéuticas es básico. Aquí debemos enfocarnos en la estandarización y protocolización de nuestras técnicas y procedimientos de acuerdo a la radiología basada en la evidencia. Además debemos velar por el cumplimiento de ellas y su evaluación y modificación periódica si es necesario. Cabe mencionar aquí la importancia de incorporar a este proceso a los tecnólogos y motivarlos: son profesionales universitarios y deberían serlo en su atención al paciente, colaboración en la elaboración de normas y protocolos y en su cumplimiento efectivo(17).

Interpretaciones muy lentas o muy rápidas: Lehr en un estudio realizado en la Universidad de Missouri en 1976 basado en radiografías de tórax, que conserva toda su vigencia en la actualidad, demostró que un mayor tiempo de lectura no disminuía el error de percepción. Los exámenes leídos incorrectamente tenían un promedio de 147 segundos y, los leídos en forma correcta, 113 segundos. En este caso debemos pensar que las imágenes deben ser analizadas en el tiempo suficiente para hacer el diagnóstico y no más(18-20). Informar solo un hallazgo y no todos: Otro elemento que influye en el error de percepción es informar un solo hallazgo en exámenes que tienen mas de uno. Está ligado a un fenómeno psicológico conocido como satisfacción en la búsqueda ${ }^{(14)}$. Por ejemplo en una radiografía de EED, informamos bellamente la úlcera duodenal, pero obviamos un evidente Borrmann I. La prevención de este inductor pasa por la revisión cuidadosa de las imágenes aún cuando visualicemos el hallazgo principal, hasta tener la seguridad que no hay una segunda lesión.

Omitir el signo radiológico o no darle la importancia que tiene: significa que vemos el hallazgo, pero no le damos el significado correcto o su valor diagnóstico apropiado y por ende, no lo informamos adecuadamente.

Los antecedentes clínicos nos sitúan en el contexto adecuado para responder la pregunta que nos formula el médico tratante con más precisión, dándole un valor agregado importante al informe radiológico. Debemos tenerlos incluso en exámenes normales: recordemos solamente la frecuencia con que los tecnólogos nos dicen "este examen es sólo de chequeo" (parte del reconocimiento médico general a que se somete una persona) y al consultar con el paciente nos cuenta que es un "chequeo" por un hipernefroma operado hace dos años y que nadie le pidió las imágenes previas porque era un "chequeo".

Efectuar informes no comparativos, es decir, no contar con las imágenes previas; éstas nos permiten elaborar un informe evolutivo que influye en la toma de decisiones clínicas y en los resultados del paciente. Es especialmente válido en el campo de la oncología, donde pequeñas variaciones en las imágenes pueden significar cambios terapéuticos radicales. No concebimos el control de una Enfermedad Pulmonar Difusa sin las imágenes previas. ¿Cuánto tiempo 
atrás? No existe consenso al respecto ni una regla estricta, dado que las patologías son muy diferentes, pero por lo menos un año antes.

Como prevención de riesgo en estos puntos deberemos incluir en nuestro plan, solicitar los antecedentes clínicos en la petición de examen radiológico; esto es especialmente importante en los sistemas de transmisión digital de imágenes, en que el paciente está menos cercano; si ello no es así deberemos designar una persona encargada de completar la información. Lo mismo en el caso de las imágenes previas: designar quién las solicitará y hacer cumplir la norma ${ }^{(21,22)}$

Carecer de conocimientos actualizados: La práctica de la radiología exige de los radiólogos como un imperativo ético y un estándar de calidad en la atención de los pacientes, el perfeccionamiento continuo como una manera de estar al día. Nuestro objetivo primario es prestar atención médica a los pacientes; como radiólogos, lo hacemos a través de imágenes de la mejor calidad técnica y para poder interpretarlas adecuadamente debemos estar al día con los avances del conocimiento de nuestro interés y en lo posible, sub especializarnos. La diferencia en el momento actual es la velocidad de incorporación de la información a través de los medios proporcionados por las nuevas tecnologías de la información, básicamente la red (www) y la incorporación de la radiología basada en la evidencia al análisis de dicha información ${ }^{(23,24)}$.

¿Cómo podemos prevenir riesgos derivados de estos factores? Cualquier esquema preventivo requiere del desarrollo de un plan para el perfeccionamiento continuo de los radiólogos como objetivo de la institución, que debería ser financiado por ambas partes. Las estadías deberían ser de una duración suficiente para cada caso en particular y realizadas en centros reconocidos como formadores de post grado nacionales o extranjeros. Este perfeccionamiento debiera dar como resultado el desarrollo de áreas de trabajo nuevas o el refuerzo y actualización de las ya existentes. Por otro lado, al planificar la forma de trabajo y organización de nuestros servicios es necesario elaborar un esquema de trabajo que permita dos cosas fundamentales; la primera es incorporar sub especialistas en las áreas más álgidas (neurorradiología, mamografía y radiología pediátrica), de manera que haga expedita la consulta de casos entre los radiólogos, lo que tiende

ii. Aliteración: Figura literaria que se forma por la repetición de un sonido, por lo general una consonante, en 2 o más palabras 0 sílabas seguidas. a disminuir la posibilidad de error en esas áreas. El segundo factor es organizar los servicios por sistemas o aparatos (tórax, abdomen, músculo-esquelético, etc.) y no por máquinas o modalidades, lo que permite racionalizar recursos, trabajar en forma integrada y mejorar la calidad en la atención de los pacientes y aumentar el grado de satisfacción profesional de los radiólogos ${ }^{(25)}$.

2 b. Error aliterativo ${ }^{i i}$ ocurre cuando el error cometido en la primera interpretación, se vuelve a repetir por el mismo radiólogo $u$ otro distinto en el control siguiente. No son errores de percepción, sino cognoscitivos, determinados por razonamientos y juicios inadecuados o erróneos. En otras palabras, el radiólogo suscribe los informes erróneos anteriores, al no pensar en forma crítica en las posibilidades diagnósticas al interpretar las imágenes. Smith sostiene que este tipo de error se produce cuando el radiólogo lee el informe anterior antes de interpretar la imagen actual y antes de revisar las obtenidas previamente. Así, esta más inclinado a adoptar la misma opinión de su colega o la suya propia previa, adoptando una noción preconcebida que lo lleva a no plantearse los necesarios diagnósticos diferenciales ${ }^{(26)}$.

Al estar relacionados con la metódica de la interpretación, la manera de gestionar el riesgo aquí tiene que ver con la secuencia rutinaria que utilizo al leer mis imágenes: cualesquiera que ella sea, debo evaluar primero la placa actual; enseguida, revisar las imágenes previas y una vez que me formé una impresión, leo los informes previos, para evitar ser influenciado y agregar un nuevo sesgo.

2 c. No revisar las imágenes con el clínico. Cuando éste llega al servicio de radiología a ver un examen que el radiólogo ya informó, pero está aún pendiente, podemos dar dos respuestas al requerimiento: una es decirle que el examen está siendo trascrito y estará listo en breve y será enviado a la sala. La otra, es recuperar las imágenes y analizarlas con el clínico. Esto que pareciera ser solo un gesto de cortesía y deferencia, es altamente beneficioso, para los pacientes desde luego, pero también para el radiólogo informante, ya que está descrito en la literatura que hay hasta un $20 \%$ de modificaciones o cambios en los informes después que el médico tratante aporta datos clínicos relevantes, especialmente en casos complejos y en modalidades altamente tecnologizadas.

La prevención de riesgo aquí es casi auto explicativa, ya que esta instancia es la última oportunidad de introducir cambios al informe antes que salga del servicio de radiología. 


\section{IV. ¿Qué hacemos si escapa a nuestro control?}

A pesar de todos nuestros esfuerzos van a haber errores / eventos adversos que no podremos manejar adecuadamente en el ámbito de jefatura de servicio. Estos casos pueden terminar en reclamos o demandas las cuales llegarán a la Auditoría Médica de la institución para su manejo y resolución judicial o extrajudicial, por una parte, y por otra, para analizar la cadena del error cometido, buscar las fallas, tomar medidas correctoras si procede y aplicarlas. Aparte de ello, deberá investigar si hubo negligencia y por ende responsabilidad civil en el acto radiológico cuestionado(30).

\section{Informe radiológico e información a pacientes}

Existen además en el proceso diagnóstico otra serie de factores que pueden llevar a cometer errores. Están relacionados con el informe radiológico y, con la entrega de información a los pacientes.

El informe radiológico es el producto comunicacional más importante en el trabajo del radiólogo; es nuestro principal nexo con el médico tratante, y es un documento médico-legal de primera importancia. Debemos normar su elaboración y asegurarnos que habrá una comunicación verbal expedita con los médicos tratantes cuando la urgencia o lo inesperado del caso así lo amerite.

En lo que respecta al formato del informe radiológico, en prosa o itemizado, debe seguir normas mínimas: descripción precisa de los hallazgos, sin comentarios impropios; impresiones diagnósticas juiciosas y criteriosas; nunca dogmáticas o inflexibles que se infieran fácilmente de la descripción. Incluir no más de dos diagnósticos diferenciales atingentes, si procede; recomendar más técnicas de imágenes, debe ser sobre la base de normas. Es de especial importancia ser cuidadosos al firmar informes por otros colegas ya que podemos estar avalando errores de percepción o logística, ya que no revisamos el examen. La modificación del informe una vez que ha salido del servicio, debe ser normada mediante la obtención de complementos (tomas, cortes o secuencias) y la introducción de un adendum al informe original|(27-28).

Comunicación de los hallazgos a los pacientes: Como regla general, la información de datos médicos, diagnósticos y tratamientos debe ser entregada al paciente por su médico tratante y así se lo comunicamos a la mayoría de nuestros pacientes. Sin embargo, éste tiene derecho a ser informado de su examen: lo sabe y en algunos casos lo exige. Al entregar este tipo de información el radiólogo tiene que ser cuidadoso y veraz, ya que es verbal y puede ser mal interpretada. En todo momento debe ser respetuoso de la persona, entregarla en un lenguaje comprensible y estableciendo un diálogo(29).

El plan de prevención de riesgos debería considerar el capacitar a aquellos radiólogos más expuestos a ser consultados (Mamografía / oncología / radiología intervencional), enseñándoles destrezas y habilidades comunicacionales para dar malas noticias.

\section{Discusión, Resumen y Conclusiones}

Sin lugar a dudas el ejercicio de la radiología se ha ido haciendo cada vez más interesante y atrayente. Los avances tecnológicos, que permiten además de diagnósticos morfológicos y funcionales cada vez más precisos, e intervencionismo terapéutico, han hecho posible una participación más directa en los equipos de médicos tratantes, con indudables mejorías en la calidad de la atención radiológica. Esto ha ido de la mano con un aumento muy marcado de los costos y de los riesgos médico legales de la atención radiológica.

En forma paralela, se ha producido aumento marcado de los costos y de los riesgos médico legales en la atención radiológica, al volverse ésta más y más compleja por los cambios desarrollados en la sociedad que se traducen en pacientes / clientes más conscientes de sus derechos, con una horizontalización en la relación médico paciente y con una participación más activa de muchos de ellos en el proceso de informarse y tomar decisiones sobre su salud. Junto a ello se ha producido un empobrecimiento de la relación antes dicha, producto muy probablemente del ambiente en el que se desarrolla actualmente el trabajo radiológico, que lleva a sentirse a los pacientes no escuchados o no tratados como personas con derechos y a sentir que las consideraciones económicas priman sobre las decisiones sanitarias. Esto los lleva a considerar que frente a cualquier resultado no esperado en su atención médica sea necesario demandar en los Tribunales, y que se indemnice los posibles daños causados.

Los profesionales nunca ganan un juicio por responsabilidad civil originado en una probable negligencia médica. Sea cual sea el resultado de la demanda, los costos en dudas personales, el tiempo de trabajo perdido, la carga emocional de la familia, y la consecuente adopción de una práctica defensiva de la radiología estarán presente, gane o pierda el juicio. El único juicio ganado por los radiólogos es el juicio evitado ${ }^{(31)}$.

De allí, la importancia de la elaboración de un 
plan de gestión de riesgos en los Servicios de Radiología, el que debe ser elaborado, financiado e implementado por la institución, con la participación de los radiólogos y tecnólogos que son los que verdaderamente conocen la cadena de producción de los exámenes y procedimientos y por ende quienes están en posición de definir los puntos peligrosos del sistema. Debería abarcar la prevención del error en el campo de los errores de logística, donde aparte de capacitar y normar las actuaciones de nuestro personal, (una manera es por cargos) necesitamos conformar un equipo ganador con empleados motivados y leales, tras una jefatura con liderazgo efectivo(32).

El otro gran sector en la prevención del error son los errores en el proceso diagnóstico en todas sus formas, siendo vital aquí reducir al mínimo los inductores del error de percepción, dado que constituyen el porcentaje mayor. Como son errores asociados a la falibilidad humana cabe preguntarnos hasta que punto las medidas serán efectivas: Los autores coinciden en que nuestro mayor esfuerzo solo impide que el error aumente o lo disminuye escasamente, sin embargo, cualquier resultado positivo es un logro. Se ha planteado que la disminución de este tipo de error, dada su génesis, podría estar en la utilización de la tecnología CAD (Computer Assisted Diagnosis) o en el campo de la inteligencia artificial aplicada al campo del diagnóstico radiológico. Esto está en investigación y aplicación inicial especialmente en el campo de la mamografía ${ }^{(33)}$.

La explosión de las nuevas tecnologías de la información es otro ámbito en el que debemos gestionar riesgos. Dado que es un área rápidamente cambiante debemos revisar nuestros planes para los registros radiológicos electrónicos, la transmisión de datos y el sistema PACS con bastante frecuencia y asesorarnos con expertos en ciencias computacionales y de la transmisión de datos en la red(34). Como corolario de esto, se hace necesario definir muy bien los roles del servicio de radiología y de la auditoria médica en la gestión de riesgos y su papel en la solución de conflictos.

En nuestro país, la atención radiológica en general tiene poco de accesible, oportuna o solidaria para un gran número de nuestros compatriotas. Tenemos en discusión una reforma de salud que asentará fehacientemente los derechos de las personas en atención de salud, especialmente el derecho a la información y la confidencialidad de los datos médicos y el consentimiento informado. También se está implementando la reforma procesal penal que hará públicos los juicios orales, con la consiguiente mediatización de los juicios por responsabilidad penal de los profesionales.

Como comentario final, la gestión de riesgos en radiología busca reducir el error y aumentar la seguridad en la atención de los pacientes, a través de intervenciones en los sistemas en que las personas trabajan y en las personas mismas, lo que redunda en una atención de mejor calidad, lo que nos permite cumplir adecuadamente nuestro objetivo primordial que es atender a los pacientes con las imágenes de la mejor calidad técnica y con calidez que no deje lugar a dudas que respetamos sus derechos como personas autónomas y que nos preocupamos por su seguridad.

\section{Bibliografía}

1. Fitzgerald R, Error in Radiology. Clin Radiol 2001; 56: 938-946.

2. Alberti KG. Medical Errors: a common problem BMJ 2001; 322:501-502.

3. Smith JP, Risk management for the radiologist AJR 1987; 149: 641-643.

4. Brenner J, Eisenberg RL, Feinstein KA, et al. Risk Management Test and Syllabus. Reston VA: American College of Radiology, 1999.

5. Goddard P, Leslie A, Jones A, Wakeley C, Kabala J, Error in radiology. Br J Radiol 2001; 74: 949-951.

6. Helmreich RL. On Error management: lessons from aviation. BMJ 2000; 320: 781-785.

7. Kohn LT, Corrigan JM, Donaldson MS eds. To err is human: building a safer health system. Washington DC: National Academy, 1999.

8. Graber M, Gordon R, Franklin N, Reducing Diagnostic errors: What's the goal? Acad Med 2002; 77: 981 - 992.

9. Smith JP, Building a Winning Team: Risk Management for the Radiologist's Employees. AJR 1998; 151:255-259.

10. Kopans DB. Breast Imaging. $2^{\text {nd }}$ ed. Philadelphia: Lippincott - Raven, 1998; 797-798.

11. Berlin L. Perceptual errors AJR 1996; 167: 587- 589.

12. Berlin L. Defending the "Missed» Radiographic Diagnosis AJR 2201; 176: 317-322.

13. Berlin $L$, The importance of proper radiographic positioning and technique AJR 1996; 166: 769-771.

14. Berbaum KS, Franken EA, Dortman DD, et al. Satisfaction of search in diagnostic radiology. Invest Radiol 1990; 25: 133-140.

15. Aideyan UO, Berbaum K, Smith WL, Influence of prior information of radiographic examination. Acad Radiol 1995; 2: 205-208.

16. Berlin L. Error in judgement AJR 1996; 166: 1259-1261.

17. Berlin L, Liability of radiologists when supervising technologists AJR 1999; 172: 285-289.

18. Lehr JL, Lodwick GS, Farrel C, Braaten MO, Virtama 
P, Kolvisto EL, Direct measurement of the effec of film miniaturization on diagnostic accuracy. Radiology 1976; 118; 257-263.

19. Nodine CF, Mello-Thoms C, Kundell HL, Weinstein SP, Time Course of Perception and Decision Making During Mammogrphic Interpretation. AJR 2002; 179: 917-923.

20. Leslie A, Jones A, Goddard P, Influence of clinical information on the reporting of $\mathrm{CT}$ by radiologists. $\mathrm{Br}$ J Radiol 200; 73: 1052-1055.

21. Berlin L, Must New Radiographs Be Compared with All Previous Radiographs or only with the Most Recently Obtained Radiographs? AJR 2000; 174: 611-615.

22. American College of Radiology: ACR standards for communication: diagnostic radiology. In: Standards. Reston, VA: American College of Radiology, 1999-2000: 1-3.

23. Armstrong JD, Morality, ethics, and radiologist's responsabilities AJR 1999; 173: 279-284.

24. The Evidence-Based Radiology Working Group. Evidence-based Radiology: A New Approach to the Practice of Radiology. Radiology 2001; 220: 556-575.
25. Maynard CD, President's Address, Radiology: Future Challenges. Radiology 2001; 219: 309-312.

26. Berlin L. Alliterative errors. AJR 2000; 174: 925-931.

27. Berlin L, Communication of the urgent finding. AJR 1996; 166: 513-515.

28. García C, Ortega D, El Informe Radiológico: «Por sus dichos los conoceréis» Rev Chil Radiol 2001; 7: 65-69.

29. Berlin L. Communicating Findings of Radiological Examinations: Whither Goest the Radiologist's Duty? AJR 2002; 178: 809-815.

30. Acosta V. Responsabilidad Civil Médica en Chile. Rev Chil Radiol 1997; 3: 55-17.

31. Wu A, Medical Error:The doctor who makes the mistake needs help too. BMJ 2000; 320: 726-727.

32. Gunderman RB, Willing SJ, Motivation in Radiology: Implications for Leadership. Radiology 2002; 225: 1-5.

33. Krupinky EA, The Future of Image Perception in Radiology. Sinergy between Humans and Computers. Acad Radiol 2003;10: 1-3

34. Eng J. Computer Network Security for the Radiology Enterprise. Radiology 2001; 220: 303-309. 